\title{
A memória midiática: projeções e sujeições no ambiente digital
}

\section{The mediatic memory: projections and subjections in the digital environment}

Diogo Andrade Bornhausen ${ }^{1}$

Norval Baitello Junior ${ }^{2}$

Resumo: O propósito deste estudo é investigar como a memória é assimilada e disponibilizada pelos meios digitais. Esta interrogação parte do valor que a memória possui para a cultura, para a comunicação e para o como é reconhecida na atualidade, projetada por sua totalidade e plenitude. Em razão disso, nota-se que sua presença ultrapassa a funcionalidade tecnológica cumulativa ao se formar como agenciadora das estratégias dos meios em narrativizar e gerenciar os saberes. Estas ocorrências, observadas a partir do Google e do Facebook, serão ainda vistas como determinantes para a formação deste ambiente comunicativo, que centra as experiências de memória a partir do automatismo e do excesso, o que ressignifica suas compreensões coletivas e subjetivas, principalmente.

Palavras-Chave: memória midiática; memória no Google; memória no Facebook

Abstract: The purpose of this study is to investigate how memory is assimilated and made available by digital means. This interrogation starts from the value that memory has for culture and for communication as it is recognized today, projected by its totality and fullness. Because of this, it is noted that its presence exceeds cumulative technological functionality by forming as an agent of media strategies in narrativizing and managing knowledge. These occurrences, observed from Google and Facebook, will still be seen as determinants for the formation of

1 Fundação Armando Alvares Penteado (FAAP). São Paulo, SP, Brasil. https://orcid.org/0000-0001-6854-5240 E-mail: diogobornhausen@gmail.com 2 Pontifícia Universidade Católica de São Paulo (PUC). São Paulo, SP, Brasil. https://orcid.org/0000-0001-7814-7633 E-mail: norvalbaitello@pucsp.br 
this communicative environment, which centers the experiences of memory from the automatism and the excess, which mainly re-signifies their collective and subjective understandings.

Keywords: mediatic memory; memory on Google; memory on Facebook 


\section{Introdução}

O uso que se faz da memória, neste ou naquele contexto social ou tecnológico,

o gênero de funcionamento que neste caso o caracteriza, a ideia que disso formam os indivíduos, determinam em grande parte o tipo de cultura em questão.

Paul Zumthor

O estudo que aqui se apresenta tem como principal objetivo indagar-se sobre como se manifesta a memória na atualidade, concentrando-se no modo como é assimilada e disponibilizada pelos meios digitais. Isto porque observa que essas tecnologias, para além de seus recursos arquivísticos, aglutinam sentidos comunicacionais e culturais profundos que lhes trazem um fascínio mnemônico de realização plena ao prometerem tudo armazenar. Nele se crê que, por meio da leitura deste cenário, seja possível elucidar a construção de um ambiente comunicativo específico, enaltecido por suas capacidades, e potencialmente construtor de um peculiar modelo de pensamento. Para tanto, propõe-se a pensar este fenômeno a partir do emprego dado à memória, dos sentidos que esta possui para a cultura, do modo como o acesso e a apreensão das informações são mediados por estes sistemas e de como os sujeitos participantes se envolvem com esta oferta.

\section{A Memória na Cultura e na Comunicação}

Procurando compreender os sentidos empregados à memória no digital, esta pesquisa confronta-se, já em seu início, com uma variada gama de acepções envolvidas com a ideia de "memória". Uma problemática que ganhou na atualidade crescente atenção em diversos campos do saber e, em especial nas Ciências da Comunicação, principalmente quando relacionada ao desenvolvimento crescente das tecnologias da informação e suas capacidades de armazenamento. 
Tomada por vezes de forma arbitrária, a memória pode ser designada lato sensu como "a faculdade de conservar e lembrar estados de consciência passados e tudo quanto se ache associado aos mesmos" (HOUAISS, 2009), o que, para aquém de uma conclusão, problematiza duas capacidades do homem: a retenção e o resgate de conteúdos. Duas categorias que abrem campo para pensar o modo como o homem buscou controlar, conquistar, recriar e unificar seu passado individual e coletivo e que deram estofo analítico para a citada diferença de interpretações. Incluem-se a isso os variados usos científicos do conceito - que em sua diversidade vão desde significações macroscópicas até a subjetivação completa dos sistemas mnemônicos. Soma-se ainda a larga difusão do senso comum, que faz aumentar sua pluralidade ao lhe conferir participação no âmbito cotidiano produzido individualmente ou socialmente. Com isso, seu uso, por vezes abusivo, faz crer que tudo é memória, o que mais impossibilita do que facilita qualquer aproximação reflexiva.

Em razão disso, de antemão, não se procurará considerá-la como instância unívoca do humano, mas, ao contrário, como um permanente desafio conceitual. Um objeto marcado por uma profunda mobilidade epistemológica que solicita um olhar que o considere um problema, um terreno movediço onde o homem sempre buscou se fincar. Propondo não se enredar nas concepções extremas e nem se invalidar na generalização, este estudo opta por pensar a memória por meio de seus conflitos e de sua interdisciplinaridade conceitual. Para tanto, a considera como ponto nodal do intelecto humano, levando em conta suas funções neurológicas e psicológicas, mas entendendo-a também como produtora de representações culturais, que procuraram apreendê-la como campo complexo e tensionado por disputas de sentidos. Isto porque, quando pensada a partir de sua participação na história do pensamento, é possível observar que os sentidos atrelados a ela se envolveram sempre em diferentes processos de produção e apropriação da cultura. Portanto, por meio da memória, o homem buscou deter e conquistar seu mundo para compreender-se, genealogicamente, neste ambiente que construiu. 
Nesse sentido, sua abrangência encontra-se aliada originariamente às representações teogônicas, deificada na emblemática imagem de Mnemosyne, mãe das Musas, recorrida e manifestada nas poesias e nos cantos gregos. Por esse motivo, a memória teve primeiramente sua atuação ligada à presentificação da origem e do saber universal, sendo uma dádiva sagrada reservada a poucos homens (ELIADE, 2013; VERNANT, 2012). Nessa concepção, a deusa significava "tudo aquilo que foi, tudo aquilo que é, tudo aquilo que será”, como afirma Hesíodo na Teogonia (2011, p. 32), sendo por meio dela revelada a Alethéa (Verdade). Esta terminologia elucida ainda que, sob o prefixo opositivo $a$ - de seu radical léthe, tem como par contrastante Lete, nome do rio que conferia o esquecimento à alma dos mortos e ao que não fosse verdadeiro.

Seu caráter transcendental - a mitologia grega lhe atribuiu um papel sobre-humano, tendo seu poder mencionado nas interpretações feitas por Platão ${ }^{3}$ e Aristóteles ${ }^{4}$-, permitiu que a memória fosse, por fim, assimilada por dois outros campos fundamentais ao pensamento ocidental, o judaico e o cristão. Seja por considerar sua participação na mística judaica, que tem nela a conservação de sua origem e a base de união de seu povo (HERSCHEL, 1995), ou nos ritos de rememoração cristãos, estendidos aos exaustivos exercícios da ars memoriae (YATES, 2007), a memória detém uma função psicológica essencial à constituição do eu, do social e do tempo, que sempre precisou ser dominado e conquistado, como afirma Jean-Pierre Vernant (1990).

Por esta razão, paralela à sua deificação, a concepção de memória foi apropriada por outros usos, ligados às grandes narrativas e às suas capacidades de criar uma unificação social baseada no tempo coletivo, tal como compreendido pelas Ciências Sociais nos séculos XIX e XX. Nas Ciências Sociais, com destaque para os estudos de Maurice Halbwachs

3 Para Platão a memória é a faculdade de acesso ao saber puro e absoluto que a alma encontrou entre as suas várias passagens terrestres e que esqueceu ao reencarnar no momento em que ingeriu a água da fonte Lete, por isso, ocupa lugar privilegiado na sua Teoria das Ideias.

4 As compreensões de Aristóteles (2012) desvinculam o ideal de memória da imortalidade ao aproximá-la de um corpo limitado e incompleto. Para ele, a fonte do conhecimento é vinculada ao sensorial, sua percepção é tratada pela imaginação, em que a memória responderia a esta imagem mental. 
(1990), a "memória coletiva” serviu às construções políticas e ideológicas criadas sobre estas sociedades. Sua laicização, como observa Jacques Le Goff (2003), contribuiu para o embasamento científico histórico, controlador e ficcionalizante de um passado que não cessa em ser destrinchado e evidenciado.

Este esforço em alçar uma compreensão e um domínio sobre a memória é verificável ao menos em outras duas perspectivas que procuravam garantir a continuidade e a permanência dos saberes e das experiências sociais. Uma envolta pela variabilidade de significados pertencentes à memória individual, foco das competências científicas que a pensaram com base em suas qualidades neurológicas, psicológicas e filosóficas, contraposta por outra, com temporalidade específica, determinista e cronológica, influenciada pelo discurso social e histórico.

Para a primeira, mais do que um condicionante social, a memória se configura como um fenômeno aberto e em dependência ao modo como as experiências individuais são geradas e gerenciadas. Por essa razão, aliam-se as funções mnemônicas ao corpo, como lugar incumbido de conservá-la para tão somente reinventá-la por meio de sua própria temporalidade. Com destaque para as interpretações realizadas por Sigmund Freud (1996, 1989) e Henri Bergson (2011), pode-se observar, em seus diferentes enfoques, a preocupação em ver que este tipo de memória é o resultado do modo como a realidade é abstraída e articulada nas imagens que o sujeito narrativiza para si. Trata-se, de acordo com Lev Vigotsky (1987), de um fenômeno decorrente de um intenso exercício imaginativo de produção - e também de encobrimento - de experiências, que determinam especialmente o modo como o indivíduo apreende seu mundo.

Ao ser capaz de imaginar o que não viu, ao poder conceber o que não experimentou pessoal e diretamente, baseando-se em relatos e descrições alheias, o homem não está encerrado no estreito círculo da sua própria experiência, mas pode ir muito além de seus limites apropriando-se, com base na imaginação, das experiências históricas e sociais alheias (VYGOTSKY, 1987, p. 21). 
Esta variação naturalmente não garante a conservação integral das informações, pois antes está sujeita a remodelações constantes, realizadas tanto pelas experiências subjetivas quanto pelas mudanças biológicas, exemplarmente abordadas nas patologias descritas por Alexander Luria e Antonio Damásio ${ }^{6}$. Diante disso, intentando garantir a perenidade das informações, um quarto enfoque sobre as possibilidades da memória foi pensado, servindo ao projeto moderno de acumulação dos saberes. Os "lugares da memória", como estudado por Pierre Nora (1993), representados nos arquivos, bibliotecas, museus e patrimônios, passam a ser detentores do passado das sociedades. Ainda que permeados pelas perspectivas históricas, sua consolidação institucionaliza-se como espaço em que, a princípio, haveria imunidade às falibilidades que as outras memórias possuíam, pois garantiria a seguridade das informações e colaboraria para sua ampliação. Sob responsabilidade das Ciências da Informação - área que abrange várias outras disciplinas como a Arquivologia, a Biblioteconomia e a Museologia -, que se encarregam da "produção, coleta, organização, armazenagem, recuperação, interpretação, transmissão, transformação e utilização da informação" (BORKO, 1968, p. 3), a memória ganha significado alheio àquele que a História lhe dava. Para esse campo, a memória, ao contrário das outras concepções, não se refere explicitamente ao passado, mesmo que nele se baseie, mas sim a uma "informação a ser revitalizada". O passado serve unicamente para ser potencializado por meio de suas variadas representações de suas inter-relações informativas, que formam um "tear informacional" integralmente disponível.

Ainda que sucinta, esta apresentação permite confirmar que a importância dada à memória nestes diferentes estágios não esteve ligada a uma concepção una, mas sim aliada ao modo como ela respondeu às

5 Em um dos casos mais emblemáticos da literatura neurológica, o médico Alexander Romanovich Luria (2006) descreve o caso de seu paciente S., que possuía uma memória inesgotável e ilimitada, sendo capaz de recordar em detalhes todas as experiências que já havia tido.

6 Contraposta à patologia do paciente de Luria, Damásio (2000) descreve o caso do paciente David, acometido por uma encefalite grave que lhe retirou a memória, o que o fez perder o significado factual das coisas a sua volta, o que significava que sua percepção de mundo se estabelecia sem referencial com o passado. 
variadas formas como as sociedades buscaram narrativizar e espacializar seu passado. Estas compreensões, fundamentalmente ligadas ao sagrado, ao social, à subjetividade e ao arquivo, demonstram que sua atuação se constituiu como um projeto no qual o homem buscou garantir a seguridade de suas informações. Neste processo, a memória passou por uma gradativa racionalização na maneira como foi observada.

Sob esta perspectiva, Vilém Flusser (2014) alia essa passagem de compreensões aos diferentes modelos de comunicação e de pensamento vividos pelo homem. Para o autor, que define a comunicação como "o armazenamento, o processamento e a transmissão das informações adquiridas” (FLUSSER, 2014, p. 33), a memória ocupa lugar central na comunicação e na cultura ao destacar que é nela que se observa a permanente negação da entropia.

Em vista disso, a memória é observada por Flusser como um campo ideológico capaz de indicar as diferentes assimilações feitas pelo homem sobre sua realidade. Para ele, desta maneira, a memória é dividida em três principais momentos: o armazenamento mítico, determinado pela cultural oral; o armazenamento mágico, manifestado na cultura material dos objetos detentores de memória; e no armazenamento historiográfico, figurado na escrita e na busca por transpassar os problemas ligados à efemeridade que os dois anteriores possuíam. Ao sintetizar as leituras anteriormente vistas, Flusser destaca que, mesmo que sempre contrastadas com o risco do esquecimento, tais disposições revelam ser a memória o maior projeto já criado pelo homem:

Todos os nossos edifícios cairão em ruína, todos os nossos livros, quadros e composições musicais estão condenados ao esquecimento, e provavelmente numerosas culturas inteiras do passado desaparecem sem deixar traço. A tendência entrópica do mundo é obviamente mais poderosa que a deliberação negativamente entrópica humana. No entanto: declarar a guerra ao absurdo do mundo é a dignidade humana (FLUSSER, s.d.).

No entanto, ainda de acordo com o autor, justamente em resposta a esse ímpeto pela "dignidade", a época atual vê-se envolta por uma nova configuração mnemônica, cumulativa dos precedentes culturais e 
propositiva de um novo cenário cognitivo. Para ele o atual avanço tecnológico oferece ao homem o sentimento de realização de ter alcançado o almejado sonho de uma memória total e, consequentemente, de ter vencido a supracitada absurdidade.

Está em curso uma conectividade em rede que se espalha como um cérebro ao redor do globo terrestre, sendo que os canais são os nervos, e os nós são as pessoas e os aparelhos: essa rede que repousa sobre a biosfera, como a biosfera sobre a hidrosfera, esse cérebro coletivo que está surgindo, que não conhece nem geografia, nem história, pois suprimiu (aufgehoben) em si a geografia e a história. Sua função nada mais é que um cruzamento de competências para secretar novas informações e aumentar a competência total do cérebro. Esse é o modelo da sociedade telemática (FLUSSER, 2014, p. 276).

Sob esta imagem de um cérebro eletrônico - que coloca Flusser em diálogo com as clássicas concepções feitas por Marshall McLuhan (2012), dos “meios como extensões do homem”, e de Pierre Lévy (2011), no que diz respeito à "inteligência coletiva” -, os meios seriam responsáveis pela realização arquivística e também por cumprir as demais idealizações culturais. Isto porque, pela supressão do espaço e do tempo, esses se capacitariam a criar uma memória que garantisse seguridade, unidade e confiança no acesso às informações.

Quando avaliadas as denominações que procuram exprimir as atuais realizações tecnológicas, tais como "sociedade do conhecimento", "cultura da democratização da informação" e "cultura do compartilhamento”, é possível notar a memória que está sendo propagada envolve-se diretamente com as ideologias mencionadas. Por ser uma qualidade ofertada por sua completude e perenidade, aparentemente livre de qualquer barreira e para todos, esta memória promovida pelo digital ganha na atualidade um caráter mágico, próprio de uma memória mítica, promovedora de um fascínio sobrenatural. Uma "razão tecnológica”, como denominada por Eugenio Trivinho (2001), que anula qualquer capacidade crítica que se possa ter sobre seus mecanismos. 
Razão tecnológica no sentido de uma razão cotidiana, pragmático-utilitária, imediatista, em relação à máquina. Implicitamente ideológica e ufanista [...] em relação à sociedade tecnológica, essa razão apresenta sempre um reencantamento feliz diante das proezas e potencialidades da tecnologia. Como tal, trata-se de uma razão não mediada pela simbolização, isto é, desprovida de autorreflexão crítica sobre suas próprias manifestações exteriores e práticas, em particular aquela em relação aos objetos tecnológicos (TRIVINHO, 2001, p. 88).

Ao analisar estas projeções na prática, em plataformas digitais de disponibilização e troca de informações, tais como o Google e o Facebook, é possível notar que nelas a sensação de fascínio surge justamente porque ultrapassam a funcionalidade meramente cumulativa de dados. No primeiro caso, não somente em seu portal de buscas, mas também em todo seu sistema, o Google descreve que o seu principal lema é: "organizar a informação mundial e torná-la universalmente acessível e útil”, o que significa tornar-se o "buscador perfeito", "algo que entende exatamente o que você quer dizer e que o leva exatamente ao que você quer" (GOOGLE, 2016). Uma intenção hiperbólica, se pensada a quantidade de dados que deveriam ser incluídos, mas que o transforma em um influente mediador dos conteúdos atualmente dispostos em rede. Como observado por Steven Levy, é este lema que garante que no Google haja uma verdade contida nas respostas, o que traz a sensação de que "se você procurou no Google, você realmente pesquisou. Se não, não” (LEVY, 2012, p. 78).

Do mesmo modo, ainda que guarde especificidades na dinâmica que propõe, o Facebook procura conglomerar e articular informações disponíveis em rede, com o diferencial de que nele os conteúdos não se referem à constituição de uma memória total, mas sim de uma memória que se constrói com a participação de seus usuários. Estes, sob a pergunta "no que você está pensando?", são convidados ao envolvimento ${ }^{7}$ e

7 Vale pontuar que, com as informações cotidianas, quem utiliza o sistema é requerido também a informar nome, email, sexo e data de nascimento, seguidos de outra lista de dados, como educação, onde e quando estudou, profissão e onde trabalha, local de residência e cidade natal, membros da família e seus respectivos graus de parentesco, o estado civil, crenças religiosas, opções políticas e gostos culturais, principalmente. 
conduzidos à condição de autores de suas próprias ideias e experiências, o que faz dessa plataforma um instrumento voltado primordialmente para a individualidade - que só então será disposta em conectividade. Por esse motivo, Marion Strecker (2012) indica que o Facebook acabou se tornando um "catálogo da terra inteira", ao ser capaz de aglutinar "as experiências das pessoas, suas memórias e suas narrativas sobre o mundo".

Narrativas e memórias que, não obstante, possuem especificidades, pois seus conteúdos são produzidos na instantaneidade nas quais as experiências ocorrem e a inserção dos registros acontece quase ao mesmo tempo do acontecido. Com a presentificação da memória, quem constrói efetivamente o lastro mnemônico, transformando o arquivo em memória experimentada onde o passado se manifesta no presente, não é o usuário, mas o próprio Facebook, que se responsabiliza por seu armazenamento e disposição. O usuário, envolvido com a produção de conteúdo, expressando suas ideias, suas experiências, angariando aceitação coletiva nas "curtidas" e comentários que recebe, é levado à condição de contribuidor da matéria-prima utilizada por esta plataforma. Estes dados colaboram para o objetivo de criar "a história de sua vida e tem três pedaços. Seus aplicativos, suas histórias e um jeito de expressar quem você é. Queremos fazer do Timeline um lugar que você se orgulha de chamar de "casa", de acordo com Mark Zuckerberg (2011).

Tanto pela função de acúmulo como de narrativização, ambas as plataformas ilustram o potencial de oferta em organizar e disponibilizar as informações. Naturalmente, tais dinâmicas visam sustentar o sucesso empresarial de ambos, denotando que o acúmulo de conteúdos é um bem claramente monetizável para estes sistemas. Contudo, justamente por terem esse valor centrado na memória, é possível questionar o quanto seus mecanismos - e todo o deslumbre que suscitam - não estão também criando efeitos sobre a comunicação estabelecida com seus participantes e com suas memórias. 


\section{A Memória Midiática}

Ao se pensar sobre a assimilação realizada pelos meios digitais, tal como indicado nas plataformas analisadas, é possível notar que a memória e suas diversas representações são conduzidas para responder algumas necessidades específicas desta época. Estas incluem a soma de suas significações em prol de uma realização idealizada, mas, principalmente, e a partir disso, de se colocar tecnicamente adequada para lidar com a diversidade informacional atualmente produzida. No entanto, esta situação também permite pensar que aquilo que, a princípio, faz esses meios possuírem uma funcionalidade exitosa e um desempenho aparentemente eficaz na articulação universal dos saberes não se desenvolve por meio da absorção literal das supracitadas faculdades mnemônicas, mas sim pela conversão dessas em estratégias eficazes para seus propósitos.

Nesse sentido, Harry Pross (1980) esclarece que tais estratégias não advêm somente das peculiaridades técnicas destes meios, mas refletem formas potenciais de dominação, abastecidas pelos próprios simbolismos provindos da cultura. Para o autor, a midiatização das comunicações implicou a ascensão de referenciais diretores, "verticalizados", capazes de sobrelevarem-se às massas e legitimarem-se em postos hierárquicos. Nessa posição, buscada por quem pretende deter o poder, os meios são aptos a se projetarem com mais facilidade mediante uma "economia de sinais", que lhes garante abrangência e otimização temporal na divulgação de suas mensagens.

Ainda de acordo com Pross (2004), a aceleração crescente das transmissões propulsionou ainda a perda gradual da proximidade dos participantes na comunicação. Os "meios terciários", como denominado pelo autor, ao vencerem os limites espaciais e temporais, responsabilizam-se pela emissão e recepção das informações, o que lhes dá contínua

8 Para Pross (1980), a ascensão do vertical encontra-se na busca pelo corpo ereto, nas edificações e nas estruturas hierárquicas da comunicação, que pretende controlar e conquistar o espaço físico e social.

9 Pross (1999) averigua que tal como a sequência ritualizada traz confiança para o tempo social e subjetivo, o sistema midiático atua como "sincronizador social", que pela repetição e ubiquidade opera sobre a sociedade a fim de coordenála. 
importância em intermediar a realidade. Estas questões tornam-se sensíveis para a formação da memória, já que sua operação é marcada pela presentificação imediata do passado, acrescida ainda de um controle empregado aos meios de imporem aos seus participantes essa imediatez, tanto no acesso quanto na retenção dos conteúdos.

A midiatização da memória, portanto, estabelece-se na forma como os valores mnemônicos são apropriados pelas dinâmicas inerentes a esses meios e em como lhes servem para legitimarem-se como concentradores e dissipadores desses conteúdos. São os meios, afinal, que preestabelecem o como essa memória será vivenciada (BORNHAUSEN, 2016, p. 98).

Ao deterem o controle sobre o gerenciamento e a disponibilização desta memória, os meios a tornam instrumentalizável de acordo com suas próprias intenções. Seja pela monetização de sua posse, como mencionado, mas principalmente por inseri-la em sua dinâmica de exposição. Todavia, se avaliadas as condições em que isso ocorre, é possível perceber uma inerente contradição. Do mesmo modo como o excesso informativo é condição primordial para a consolidação da oferta totalizante de dados, a dinâmica expositiva dos meios também valoriza a novidade, o que confronta a valia do que não ocupa mais o espaço de atenção. Dessa maneira, sua contradição se figura em um discurso que exalta o acesso à informação e que, na prática, valoriza continuamente somente o novo, ou seja, os conteúdos que alçarão o status de detentores de visibilidade. Para Norval Baitello (2005) esta situação conduz ao que denomina como "crise de visibilidade", que define como:

A crise de visibilidade não é uma crise das imagens, mas uma rarefação de sua capacidade de apelo. Quando o apelo entra em crise, são necessárias mais e mais imagens para se alcançar os mesmos efeitos. O que se tem então é uma descontrolada reprodutibilidade (BAITELLO, 2005, p. 14).

A dinâmica a que se refere Baitello, ao ser averiguada no Google e no Facebook, é percebida como intrínseca ao modo como estes sistemas lidam com seus conteúdos. Em ambos os casos, os instrumentos algorítmicos que regulam o acesso demonstram que, se uma página não tiver 
um número de visualizações expressivo ou não aderir aos mecanismos que possibilitam a elas estarem no topo dos resultados, vão gradativamente perdendo importância, ao ponto de sequer serem mostradas em uma busca mais aprofundada.

No caso do Google, a ferramenta responsável por esse controle é denominada como PageRank ${ }^{\mathrm{TM}}$. Seu funcionamento, creditado à máquina e por isso anunciado como imparcial, opera tal como uma "aranha", que rastreia e privilegia as informações mais relevantes ${ }^{10}$. Também são ranqueadas na ordem que se acredita ser o mais próximo da intenção de busca. Em teste realizado para averiguar esta operação, observou-se que a composição desta oferta é acompanhada com as expressões "você quis dizer isso..." e "estou com sorte", bem como o "preenchimento automático” e o ranqueamento das páginas expostas, insinuando qual das informações é a ideal. Contudo, a fim de verificar esta dinâmica, pesquisou-se ${ }^{11}$ a tag "google" no próprio Google, o que permitiu chegar ao valor de sete bilhões e trezentos e oitenta milhões de resultados disponíveis, tendo sido necessários 0,41 segundo para se chegar a eles. Buscando compreender as operações do sistema, decidiu-se ir até o final da busca. Na primeira tentativa, foi possível chegar até a página 16, sendo que cada página acumula 10 links, totalizando 162 páginas possíveis de serem visualizadas, pois ao final aparece a seguinte mensagem: "para mostrar os resultados mais relevantes, omitimos algumas entradas bastante semelhantes aos 162 resultados já exibidos. Se desejar, você pode repetir a pesquisa incluindo os resultados omitidos". Com a intenção de continuar comprovando a eficácia das buscas, optou-se por repetir o procedimento, o que na segunda vez permitiu chegar até a página 53, totalizando 530 resultados disponíveis, sendo que a partir desse ponto o

10 De acordo com o Google (2016), ao explicar o seu funcionamento algorítmico, é afirmado que: "Sites importantes, de alta qualidade, recebem uma nota de avaliação maior, que o Google grava a cada busca feita (...) Assim, o Google combina os resultados de alta qualidade com a busca que você está realizando para que o resultado seja o mais relevante possível".

11 Ao procurar averiguar as informações fornecidas pelo Google, esta pesquisa considerou a análise dos dados fornecidos por esta plataforma quando as buscas são realizadas. Os valores relativos a tempo e quantidade de dados disponibilizados e as afirmações referentes à relevância são informadas pelo sistema, o que comprova o mencionado direcionamento dos conteúdos. 
Google não permite mais estender a pesquisa. Dessa forma, percebe-se que o valor de dados informados na procura e o real acesso que se tem, considerando a segunda busca, é de 0,0000071816\% do total anunciado, evidentemente bastante inferior ao prometido.

Em relação semelhante, no Facebook o algoritmo é denominado EdgeRank, por meio do qual a concentração de seu funcionamento está no que o programa acredita ser válido de ser visto e acessado, operando a partir da relação entre Afinidade/Familiaridade, Peso/Relevância e Tempo/Depreciação de conteúdo (FACEBOOK, 2017). No primeiro caso, o algoritmo mensura o nível de relacionamento entre o usuário e as informações que acessa, ou seja, a quantidade de vezes que determinada pessoa ou marca é "curtida", comentada e visualizada por ele. Aliado a esse critério, o peso ou a relevância dos conteúdos são determinados pelo Facebook com base no quão envolvente é uma informação, como os comentários que valem mais do que "curtidas" ou imagens que ganham maior notoriedade do que os textos. E, por fim, o tempo de publicação ou o quanto ela é depreciável, similar ao critério de novidade proposto pelo Google, caracterizado pela valorização das informações mais atuais em detrimento das antigas, estimulando uma maior quantidade de acessos. A incluir o selecionamento do que será visto na barra de rolagens que não cessa em se reciclar, fica clara a incumbência disposta e concedida ao Facebook de nortear a validade das informações, rememorando e narrativizando as experiências dos usuários. Como comprovado por Chris Ingraham (2015) em estudo realizado para o Washington Post, este funcionamento faz com que cerca de $60 \%$ dos conteúdos que estariam disponíveis não são postos à visualização. A ocorrência denota que, diante do vasto campo de informações, o sistema tende a afunilar determinados conteúdos, personalizados para usuários e grupos específicos, sempre de acordo com suas próprias afinidades. Estes conteúdos obedecem à visualidade disposta por seu layout, que, por funcionar em sistema de rolagem, tende a encobrir informações passadas em função das novidades recém-publicadas. 
Nesse sentido, a memória nestes meios é conduzida ao seu oposto, à obsolescência, pois participa de uma oscilação entre o que tem mais ou menos chances de ser acessado dentre as informações que irão aparecer e desaparecer de acordo com as intenções dos programas. Como consequência, o próprio usuário também passa a lidar com esta variação, já que é ele quem se vincula às informações, seja depositando-as ou acessando-as. E é a ele que recorre a busca pela visibilidade a fim de alçar a exposição.

Para Flusser (2014), estando diante desta terceirização mnemônica promovida pelo digital, o usuário se confrontaria com dois caminhos possíveis: a) a extrema redundância informativa resultante de um excesso de conteúdos disponíveis; b) a "des-ideologização" da memória, que permitiria a plena criatividade humana, em que toda necessidade de posse seria delegada ao aparelho, concedendo ao homem a articulação livre dos saberes. Uma situação ou outra dependeria do modo de manter a relação com estas informações e a maneira como aparelho e usuário se correspondem.

Se pensada a partir das contribuições de Flusser (2011), a relação estabelecida entre o aparelho que intenta realizar o projeto mnemônico e seus usuários, nomeados pelo autor como "funcionários", é de que o primeiro visa a ser um "brinquedo que simula um tipo de pensamento" (FLUSSER, 2011, p. 17). Desse modo, a memória se disponibilizaria de acordo com as regras inscritas no funcionamento do próprio aparelho, no seu programa, e em como elas regulam a forma como seus participantes atuarão, segundo demonstrado nos funcionamentos algorítmicos. A estes, de acordo com o autor, restaria brincar com ele por meio do que foi preestabelecido.

Nesta espécie de jogo proposto, travestido na exacerbação informativa comprovada nas duas plataformas apresentadas, o sujeito participante se crê controlador, pois é ele que opta quais memórias quer acessar ou quais voluntariamente coloca dentro do próprio sistema, que somente se incumbe de dispor isso ao acesso. Sob este sentido é que Flusser vislumbra o caminho criativo para se lidar com os saberes disponíveis. 
Contudo, como observa Baitello (2010), mais próxima do que a autonomia, está a automatização da maneira como este acesso se constrói e se projeta:

Fica assim sublinhada uma marca não apenas do aparato técnico, mas também de todo o aparelho social e midiático contemporâneo: a dispensa do pensar e do querer, pois esta tarefa de pensar e de querer é simplesmente assumida pelo aparelho, libertando o funcionário de tal pesado e difícil ônus, permitindo a ele apenas entrar no jogo das possibilidades do aparelho, uma atitude de entrega, portanto, um deixar-se devorar (BAITELLO, 2010, p. 21).

Em ambas as leituras a questão sobre a aquisição do conhecimento comprova-se como importante elemento participante desta memória. De acordo com Nicholas Carr (2011), ao refletir sobre os efeitos cerebrais causados pela velocidade com que as informações se apresentam, há uma possível saturação do próprio indivíduo em reter tudo que a ele se exibe:

O influxo de mensagens competindo entre si, que recebemos sempre que estamos on-line, não apenas sobrecarrega a nossa memória de trabalho; torna muito mais difícil para os lobos frontais concentrarem nossa atenção em apenas uma coisa. O processo de consolidação de memória sequer pode ser iniciado. Quanto mais usamos a web, mais treinamos nosso cérebro para ser distraído (CARR, 2011, p. 264-265).

Nesta situação, ainda que teoricamente a alternativa criativa apresentada por Flusser fosse possível, as leituras apresentadas ajudam a entrever que a própria ação mnemônica, originariamente uma preocupação do homem, pode estar sendo colocada em segundo plano, ao menos quando é esse sujeito o responsável por ela. Esta é uma condição comprovada também no recente estudo promovido pelos psicólogos Betsy Sparrow, Jenny Liu e Daniel M. Wegner (2011). Sintomaticamente denominado "Efeito Google", eles sugerem que a internet hoje é vista como um "banco de dados pessoais", uma espécie de "memória externa” que influi na capacidade de retenção de informações dos usuários. Para eles, 
essa ocorrência se desenvolve, pois a confiança creditada sobre o sistema sobrepõe-se ao exercício de busca e apreensão de diferentes resultados.

Segundo Baitello (2012), ao observar os sentidos subjacentes dessas dinâmicas, essa condição exprime-se por uma sedação perceptiva condicionada pelo próprio ambiente em que o indivíduo se coloca. Não somente pela posição física do indivíduo ao se relacionar tecnologicamente, mas pelo acomodamento perceptivo de receber as informações da maneira como são disponibilizadas, a sua sedação confirma o quanto essa condição afeta profundamente e efetivamente a sua própria memória, já que é o programa quem controla os conteúdos ideais de acesso.

A sedação ou sua letargia, do mesmo radical leth- de esquecimento, confrontam-se, assim, com muitos dos pressupostos filosóficos e psicanalíticos [...] em que a memória foi vista como um processo extremamente complexo, que envolve a percepção e a reelaboração permanente no modo como o indivíduo se relaciona com seu meio, como resultado das experiências, práticas e observações que teve. Estabelecida conscientemente ou não, a memória se refere ao aprendizado do indivíduo, não limitado ao resgate imediato da lembrança - tal como um arquivo -, mas envolvido com a permanente influência das emoções e de sua própria imaginação (BORNHAUSEN, 2016, p. 110).

Neste mesmo sentido, Dietmar Kamper (2016), indo contra as leituras que exaltam a terceirização mnemônica, esclarece que é sob a "força da imaginação" (Einbildugskraft) que a memória fundamentalmente se constitui, historicamente e psicologicamente. Ela, ao contrário dessa memória midiática, está em permanente renovação, já que baseada nas imagens internas pensadas e retrabalhadas corporalmente (KorperDenken). Para o autor, é justamente essa capacidade imaginativa que se vê diminuída com a crescente abstração criada pelo midiático. Diante desta situação, as respostas prontas e imediatas oferecidas por esta memória implicam a não geração efetiva de memória para os indivíduos, mas sim uma literalização do conhecimento e da apreensão do mundo, cada vez mais mediado por esses programas. 


\section{Considerações finais}

Sob esta perspectiva, é possível concluir que o ambiente midiático encarregado por esta memória, fruto de toda idealização cultural, que proporcionaria a articulação libertadora das informações - em menção à afirmação de Flusser -, parece não corresponder aos objetivos para que foi inicialmente pensado. Isso porque ele próprio se vê revestido por condicionantes, como a saturação de conteúdos e automatismos em sua disponibilização, que o encaminham a uma outra configuração. Como demonstrado no decorrer desta análise, a memória mostra-se mais como uma imagem ideal conquistada por estas tecnologias do que uma efetiva realização. Sua principal consequência, portanto, está na evidente alteração da maneira como as informações são recebidas e apreendidas, com claro impacto sobre a comunicação que está sendo gerada.

\section{Referências}

ARISTÓTELES. Parva naturalia. São Paulo: Edipro, 2012.

BAITELLO, N. O pensamento sentado. Sobre glúteos, cadeiras e imagens. São Leopoldo: Unisinos, 2012.

Paulo: Paulus, 2010.

A serpente, a maçã e o holograma: esboços para uma teoria da mídia. São Las capilaridades de la comunicación. In: SARTORI, R.; MUÑOZ, B.; VALENZUELA, V. Diálogos culturales. Interdisciplinas para la comunicación. São Paulo: Annablume; Valdivia: Universidad Austral de Chile, 2007. p. 20-55.

. A era da iconofagia. Ensaios de comunicação e cultura. São Paulo: Hacker

Editores, 2005.

BERGSON, H. Memória e vida. São Paulo: Editora WMF Martins Fontes, 2011.

BORKO, H. Information science: what is it? In: American Documentation, Chicago, v. 19, n. 1, p. 3-5, 1968.

BORNHAUSEN, D. A. A Midiatização da Memória: Projeções, regulações e sujeições no ambiente digital. 2016. 147f. Tese (Doutorado em Comunicação e Semiótica). Pontifícia Universidade Católica de São Paulo, São Paulo. 2016.

CARR, N. A geração superficial: o que a Internet está fazendo com nossos cérebros. Rio de Janeiro: Agir, 2011. 
DAMASIO, A. O mistério da consciência. São Paulo: Companhia das letras, 2000. ELIADE, M. Mito e Realidade. São Paulo: Perspectiva, 2013.

FACEBOOK (2017). Noções básicas de privacidade. Disponível em: <https://www.facebook.com/about/basics\#toptopics>. Acesso em: 11 set. 2018.

FLUSSER, V. Comunicologia: reflexões sobre o futuro. As conferências de Bochum. São Paulo: Martins Fontes, 2014.

Filosofia da caixa preta. Ensaios para uma futura filosofia da fotografia. São Paulo: Annablume, 2011. Memória. [Sem Data] 2683_MEMORIA [V.2]. Arquivo Vilém Flusser São Paulo.

FREUD, S. Uma Nota Sobre o Bloco Mágico. In: Obras Psicológicas Completas de Sigmund Freud. Vol XIX. Rio de Janeiro: Imago Editora, 1996. p. 320-385 Lembranças encobridoras. Rio de Janeiro: Imago, 1989.

GOOGLE (2016). Sobre o Google. Disponível em: <http://www.google.com/about/ company/>. Acesso em: 20 jan. 2017.

HALBWACHS, M. A memória coletiva. São Paulo: Ed. Revista dos Tribunais, 1990. HERSCHEL, A. J. A passion for truth. Nova York: Jewish Lights Publis, 1995.

HESIODO. Teogonia. São Paulo: Martin Claret, 2011.

HOUAISS, A. Dicionário Houaiss da língua portuguesa. Rio de Janeiro: Objetiva, 2009.

INGRAHAM, C. What you don't know about Internet algorithms is hurting you. (And you probably don't know very much!). The Washington Post, 2015. Disponível em: <https:/www.washingtonpost.com/news/the-intersect/wp/2015/03/23/ what-you-dont-know-about-internet-algorithms-is-hurting-you-and-you-probably-dontknow-very-much/?noredirect=on\&utm_term $=.5 \mathrm{e} 83 \mathrm{cdd} 295 \mathrm{f} 7 \mathrm{>}$. Acesso em: 22 ago. 2018.

KAMPER, D. Mudança de horizonte: o sol novo a cada dia, nada de novo sob o sol, mas... São Paulo: Paulus, 2016.

LE GOFF, J. História e Memória. Campinas: Unicamp, 2003.

. Enciclopédia Einaudi. Vol. 1 Memória - História. Lisboa: Imprensa Nacional; Casa da Moeda, 1997.

LEVY, P. A inteligência coletiva: por uma antropologia do ciberespaço. São Paulo: Loyola, 2011.

LEVY, S. Google: a biografia. São Paulo: Universo dos Livros, 2012.

LURIA, A. R. A mente e a memória: um pequeno livro sobre uma vasta memória. São Paulo: Martins Fontes, 2006.

MCLUHAN, M. Os meios de comunicação como extensões do homem. São Paulo: Cultrix, 2012.

NORA, P. Entre memória e história: a problemática dos lugares. São Paulo: EDUC, 1993.

PLATÃO. Teeteto. Belém: UFPA, 2001.

Fedon: diálogo sobre a alma e morte de Sócrates. São Paulo: Martin Claret, 2003. 
Menon. São Paulo: Loyola, 2003.

. O banquete. Porto Alegre: L\&PM, 2009.

PROSS, H. Aceleração e perda. In: CONTRERA, Malena Segura; GUIMARÃES, Luciano; PELEGRINI, M.; SILVA, M. (Orgs.) O espírito do nosso tempo: ensaios de semiótica da cultura e da mídia. São Paulo: Annablume; CISC, 2004. p. 65-89. Atrapados en la red mediática. Orientación en la diversidad. Hondarribia: Argitaletxe Hiru, 1999. La violencia de los símbolos sociales. Barcelona: Anthropos, 1989. . Estructura simbólica del poder. Barcelona: Editora Gustavo Gili, 1980.

PROSS, H.; BETH, H. Introducción a la ciencia de la comunicación. Barcelona: Anthropos, 1987.

SPARROW, B.; LIU, J.; WEGNER, D. M. Google Effects on Memory: Cognitive Consequences of Having Information at Our Fingertips. Science Magazine, v. 333, Issue 6043, p. 776-778, 2011. Disponível em: <http://www.sciencemag.org/content/333/6043/776. full.pdf $>$. Acesso em: 4 out. 2017.

STRECKER, M. Novo Catálogo da Terra Inteira, Facebook transforma pessoas em marqueteiros de si mesmos. UOL Tecnologia, 2012. Disponível em: <http://tecnologia.uol. com.br/noticias/redacao/2012/05/18/novo-catalogo-daterra-inteira-facebook-transforma-pessoas-em-marqueteiros-de-si-mesmos.htm>. Acesso em: 4 out. 2017.

TRIVINHO, E. O mal-estar da teoria: a condição da crítica na sociedade tecnológica atual. Rio de Janeiro: Quartet, 2001.

VERNANT, J. Mito e religião na Grécia Antiga. São Paulo: Martins Fontes, 2012.

. Mito e pensamento entre os gregos: estudos de psicologia histórica. Rio de Janeiro: Paz e Terra, 1990.

VYGOTSKY, L. Imaginación y el arte en la Infancia. Cidade do México: Hispánicas, 1987.

YATES, F. A arte da memória. Campinas: Ed. Unicamp, 2007.

ZUCKERBERG, M. Facebook muda página pessoal para linha do tempo e altera botão 'curtir'. Globo Tecnologia, 2011. Disponível em: <http://gl.globo.com/tecnologia/ noticia/2011/09/facebook-apresenta-linha-dotempo-para-registrar-vida-do-usuarionosite> . Acesso em: 22 ago. 2018.

ZUMTHOR, P. Tradição e esquecimento. São Paulo: Hucitec, 1997. 


\section{Sobre os autores}

Diogo Andrade Bornhausen - Doutor em Comunicação e Semiótica pela Pontifícia Universidade Católica de São Paulo, professor da Fundação Armando Alvares Penteado, Vice-diretor Científico do Arquivo Vilém Flusser São Paulo e Pesquisador do CISC (Centro Interdisciplinar de Semiótica da Cultura e da Mídia).

Norval Baitello Junior - Doutor em Ciências da Comunicação pela Universidade Livre de Berlim. Professor titular do Programa de Estudos Pós-Graduados em Comunicação e Semiótica da PUC-SP e Diretor Científico do Arquivo Vilém Flusser São Paulo.

Data de submissão: 17/12/2017

Data de aceite: 20/09/2018 